\title{
ANALYSIS OF THE CORROSION RESISTANCE OF AIRCRAFT STRUCTURE JOINTS WITH DOUBLE-SIDED RIVETS AND SINGLE-SIDED RIVETS
}

\author{
Paulina Kamińska • ORCID 0000-0002-3840-5615 \\ Piotr Synaszko • ORCID 0000-0002-7884-0582 \\ Patryk Ciężak • ORCID 0000-0002-7389-7109 \\ Krzysztof Dragan • ORCID 0000-0003-1857-227X
}

\begin{abstract}
Air Force Institute of Technology, ul. Ks. Boleslawa 6, 01-494 Warsaw, Poland
paulina.kaminska@itwl.pl,piotr.synaszko@itwl.pl,patryk.ciezak@itwl.pl, krzysztof.dragan@itwl.pl
\end{abstract}

\begin{abstract}
An important factor having a negative impact on the technical condition of aircraft structure elements is the adverse effect of the atmosphere, which causes formation of corrosion in aircraft structures, especially in riveted lap joints. The electric potential difference between the sheet material and the rivet, in the presence of humid air, may cause electrochemical corrosion. The paper presents specimens that imitate the repair on the Mi-24 helicopter with the use of blind rivets in places where solid double-sided rivets could not be used. The aim of the research was to assess the corrosion resistance of lap joints with the use of single-sided and double-sided rivets. The analysis of corrosion resistance was carried out based on accelerated aging tests in a salt spray chamber. The salt chamber tests were aimed at determining the changes taking place in the specimens exposed to the marine environment. In the course of periodic observations changes in the mass of the specimens and in the form of corrosion losses were recorded. These activities were aimed at determining whether the exposure of specimens in the salt chamber causes electrochemical corrosion or pillowing. In addition, the specimens were subjected to static strength tests to assess the effect of corrosion on the strength properties of riveted joints.
\end{abstract}

Keywords: rivet joints, double-sided rivets and one-sided rivets, corrosion, accelerated ageing tests

Article Category: Research Article

\section{INTRODUCTION}

The atmospheric environment in which aircraft are operated has a negative impact on their technical condition. In more aggressive environment, i.e. at the seaside, aircraft 
are more vulnerable to corrosion damage [1]. This is due to high salinity of the air. Corrosion of aircraft structures often occurs in the joints of elements. This is related to the difference in electrochemical potentials between the material of the aircraft skin and the rivets. The potential difference in the presence of humid air can cause electrochemical corrosion $[2,3]$.

Rivet joints are exposed to intercrystaline corrosion because of the presence of significant stress concentrations [4]. Already in the riveting process, the internal stresses which exceed the yield strength locally are generated. Corrosion processes on rivet joints in overlap structures are conducive to the so-called "pillowing". One of the most spectacular examples of aviation accident caused by the occurrence of corrosion-related phenomenon is the Boeing 737 Aloha Airlines disaster. The plane accident was caused by the occurrence of multiply site damage (MSD) in lap joints of the fuselage skin panels. This phenomenon is due to the simultaneous occurrence of two unfavorable factors: corrosion and fatigue loading of the structure $[5,6]$.
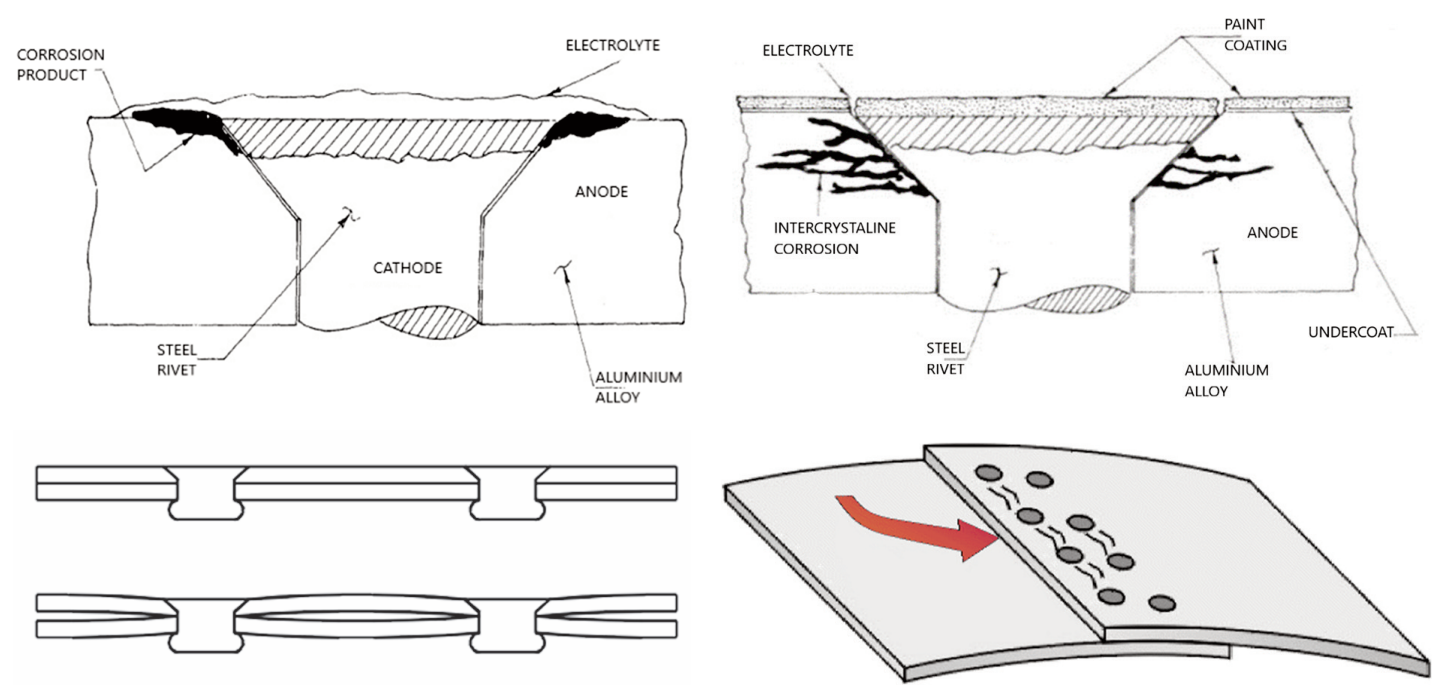

Fig. 1. Scheme of a) electrochemical corrosion, b) intergranular corrosion, c) pillowing and d) multiply site damage [5,6].

These types of examples show how important it is to predict the appearance of corrosion, detect corrosion and correctly remove of corrosion products or repair damaged elements. For this purpose, research works on corrosion resistance of metals and their protection are carried out. Tests could be conducted in natural conditions by exposing the specimens to atmospheric conditions, however it is very time consuming. It is also possible to conduct accelerated laboratory tests with the use of appropriate climatic chambers.

Accelerated tests involve enhancing one or several corrosive factors in such a way that the corrosion process takes place faster than under in-service conditions. Most of the tests use increased relative humidity and temperature and optional salt solution spraying, which allows imitating the sea atmosphere. The salt spray method carried out in accordance with the ASTM B117 standard gives approximately one hundred times 
acceleration of corrosion processes. Accelerated testing significantly shortens the duration of the corrosion test, although test conditions rarely occur in real life. Nevertheless, the results of accelerated tests can be equated to the time in real exploitation conditions of the elements [7]. In order to determine corrosion resistance, it is also possible to carry out long-term tests at corrosion stations.

Corrosion or Weathering stations are special areas with specimen racks set up. On these racks specimens are exposed to environmental conditions. The racks have to be secured against undesirable displacement and specimens are placed in such a way that they do not change their position. Corrosion stations allow periodic observation of specimens being subject to the atmospheric corrosion test [1].

The aim of this paper is to assess the corrosion resistance of aircraft structure joints using one-sided and double-sided rivets.

\section{EXPERIMENTAL TESTING}

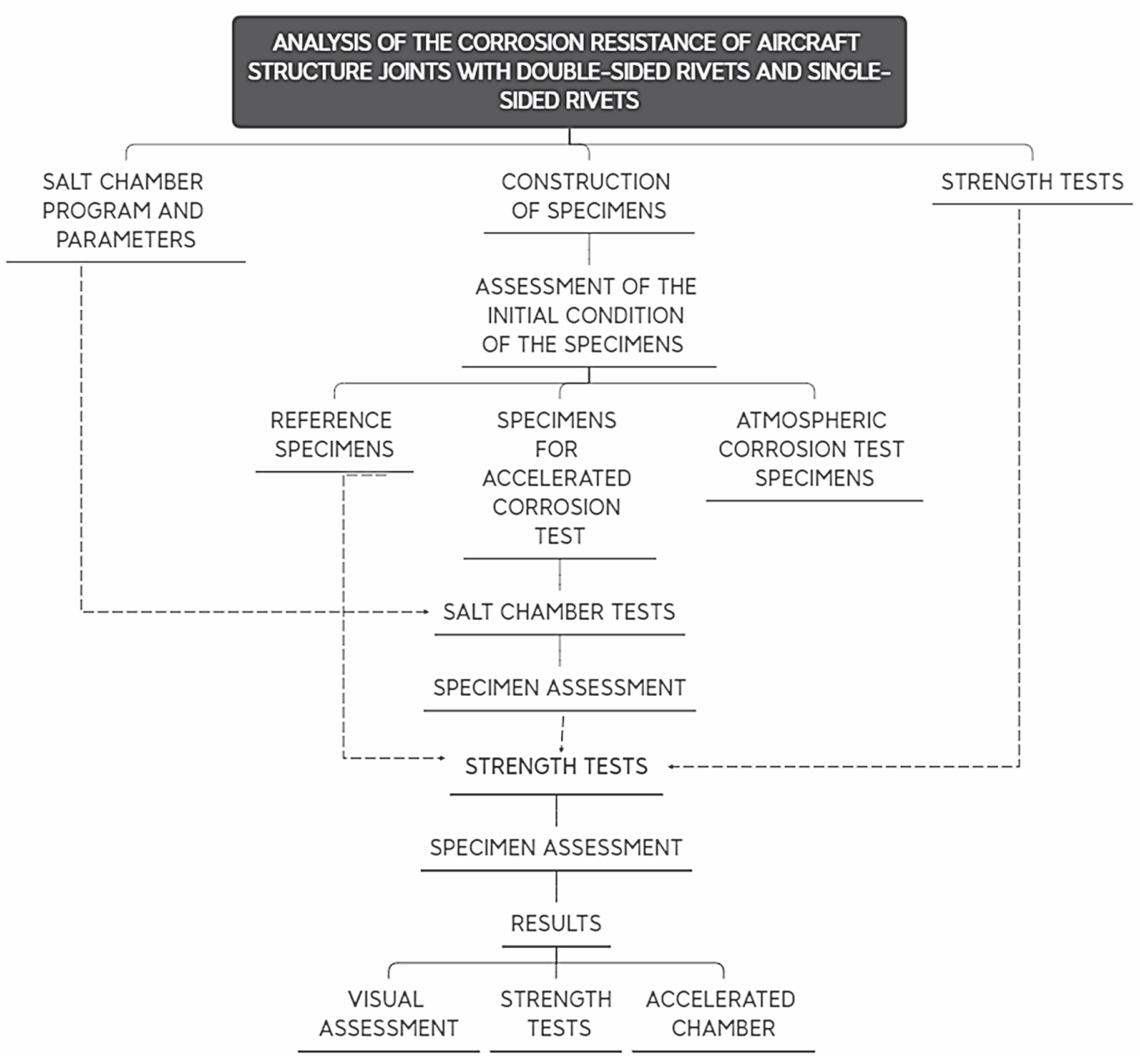

Fig. 2. Scheme of experimental testing. 


\section{Methodology}

The first stage of the research was developing the specimens structure, selecting parameters for accelerated tests, and strength tests.

Before proceeding with the exposure of the specimens, an evaluation of the initial state of all specimens was performed. For this purpose, the initial weight of each of the specimens was recorded, visual inspection of the outer surface was performed, and images showing the surfaces of the specimens were recorded. The mass measurement for each specimen was carried out three times and the average of the measurements was calculated. The specimens were weighed on a WPS $2100 / \mathrm{c} / 2$ analytical balance with a measuring range of $0,020-210.000 \mathrm{~g}$ and a measuring accuracy of $0,001 \mathrm{~g}$.

Following the initial state assessment, the corrosion specimens were divided and exposed to various conditions:

1. Warehouse exposure (reference specimens) - storage of specimens not subjected to aging tests, in a room with low humidity (below 40\%), at room temperature and without access to sunlight.

2. Accelerated salt spray aging - specimens were subjected to accelerated aging in the salt spray chamber in accordance with ASTM B117 "Standard Practice for Operating Salt Spray (Fog) Apparatus".

3. Aging of specimens at a weathering station - the specimens were subjected to natural atmospheric conditions.

The corrosion resistance analysis was carried out based on accelerated aging tests in a salt chamber. The corrosion test time was equivalent to 10 years of operating on aircraft in the marine environment.

Given that the salt spray tests carried out with the ASTM B117 A standard accelerate the process 100 times, in order to reproduce a 10-year long exposure to an aggressive environment it was assumed that the specimens should be tested in the salt spray chamber for approximately 35 days. As a result of periodic observation (every 7 days), changes in the mass of the specimens and in the form of corrosion products were determined in the area of the connection between the sheet and the rivet.

Some of the specimens were tested at a corrosion station. However, the specimens were placed at the station about six months ago, therefore these specimens will not be discussed here. The results following prolonged exposure will be compared with the results of tests conducted in the salt spray chamber in the future.

Reference specimens and specimens subjected to accelerated aging in the salt spray chamber were subjected to a static tensile test. The strength tests were aimed at determining the influence of accelerated tests on the load capacity of riveted joints. During the tests, the loads at which the specimens were damaged were recorded. The load capacity test was carried out with the use of the ZD 10 testing machine by Fritz HECKERT.

After performing the strength tests, the specimens were assessed using a visual method. The form of specimen destruction was determined based on the fractures observed. 


\section{Testing specimen}

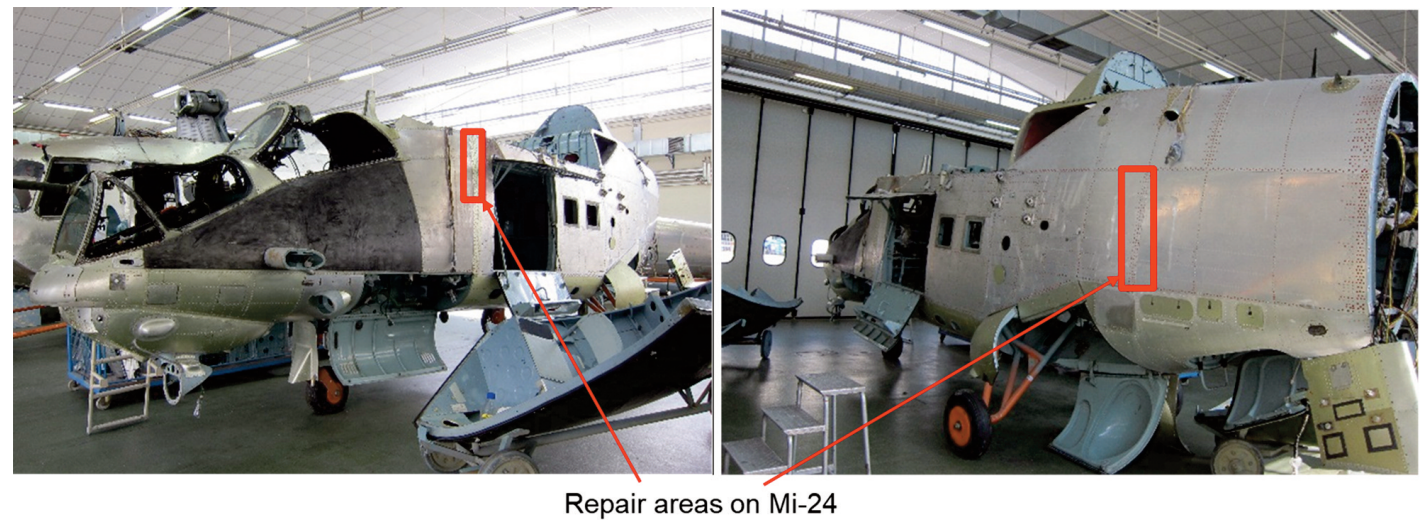

Fig. 3. Pictures of repair areas on Mi-24.

The test objects are specimens of aircraft structures joints riveted with double-sided and one-sided rivets, that reflects the repairs using blind rivets, the Mi-24 helicopter. Blind rivets are used in areas where it is impossible to use solid double-sided rivets [8]. Repairs of this type were used in the areas of rivet joints on the central part of the Mi-24 helicopter fuselage (Fig. 3).

As part of this research work, 8 series of specimens for corrosion tests were prepared. The specimen series differed from each other in the method of corrosion protection and the method of joining the structures. The specimens were in the form of lap joints consisting of three types of flat aluminum sheets: anodized in sulfuric acid and sealed in potassium dichromate, claded and anodized extracted from the Su-22 aircraft.

Three types of rivets were used in the joints:

- double-sided mushroom head rivets with a diameter of $4 \mathrm{~mm}$ made of aluminum alloy, which are currently used in the construction and repair of Mi-24 helicopters,

- one-sided titanium alloy fasteners - with a round head,

- one-sided aluminum alloy fasteners - (Huck rivets).

Specimens from each series were selected for testing in a corrosion chamber, for testing in a corrosion station, and as reference specimens. The specimens were marked sa shown in Figure 4.

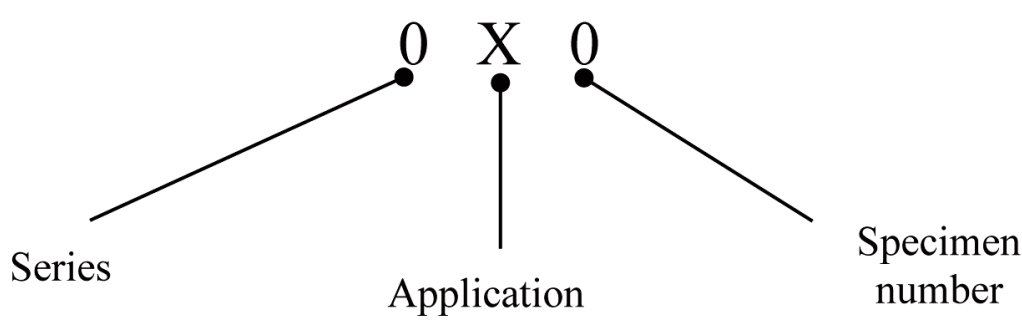

Fig. 4. Specimen designation scheme. 
Table 1. Description of the specimen marking in accordance with their intended use.

\begin{tabular}{|c|c|c|}
\hline \multicolumn{2}{|c|}{ Application } & Specimen number \\
\hline Designation(X) & Description & $1-3$ \\
\hline $\mathbf{K}$ & $\begin{array}{c}\text { Specimens for accelerated } \\
\text { corrosion tests }\end{array}$ & 1 \\
\hline $\mathbf{A}$ & $\begin{array}{c}\text { Atmospheric corrosion test } \\
\text { specimens }\end{array}$ & 1 \\
\hline
\end{tabular}

Table 2. Description of the specimen series.

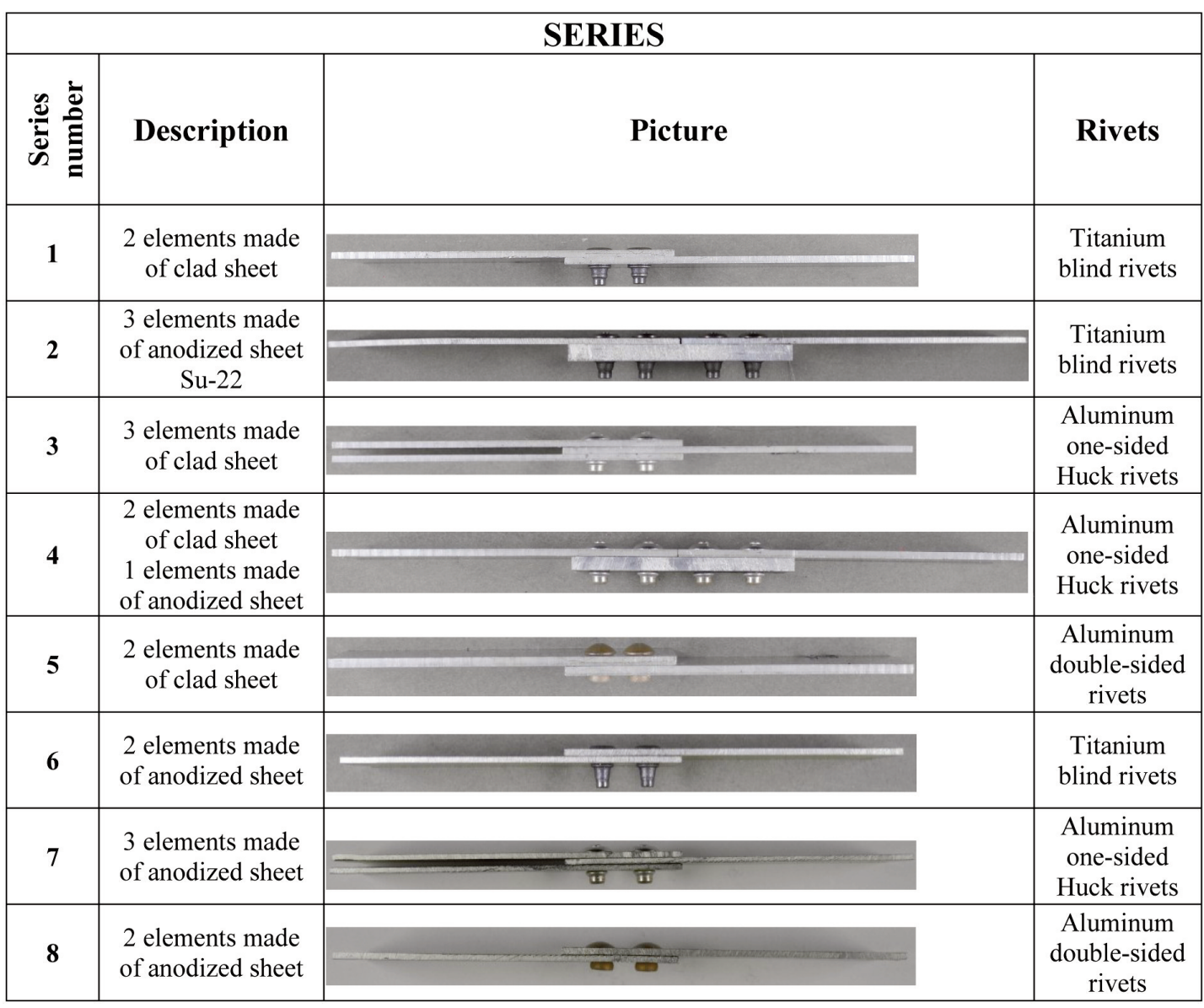

\section{RESULTS}

\section{Visual assessment}

The results of the visual assessment are photos showing the external surface of the specimens. The Figure 5 shows one photo for each series of specimens before and after five weeks of salt spray testing. 
Before salt spray testing, shallow scratches were recorded on the surface of specimens of all series. However, there was no corrosion on the sheets or the rivets. For the corrosion tests, the side surfaces of the specimens were not protected to allow the free flow of the salt solution between the sheets joined.

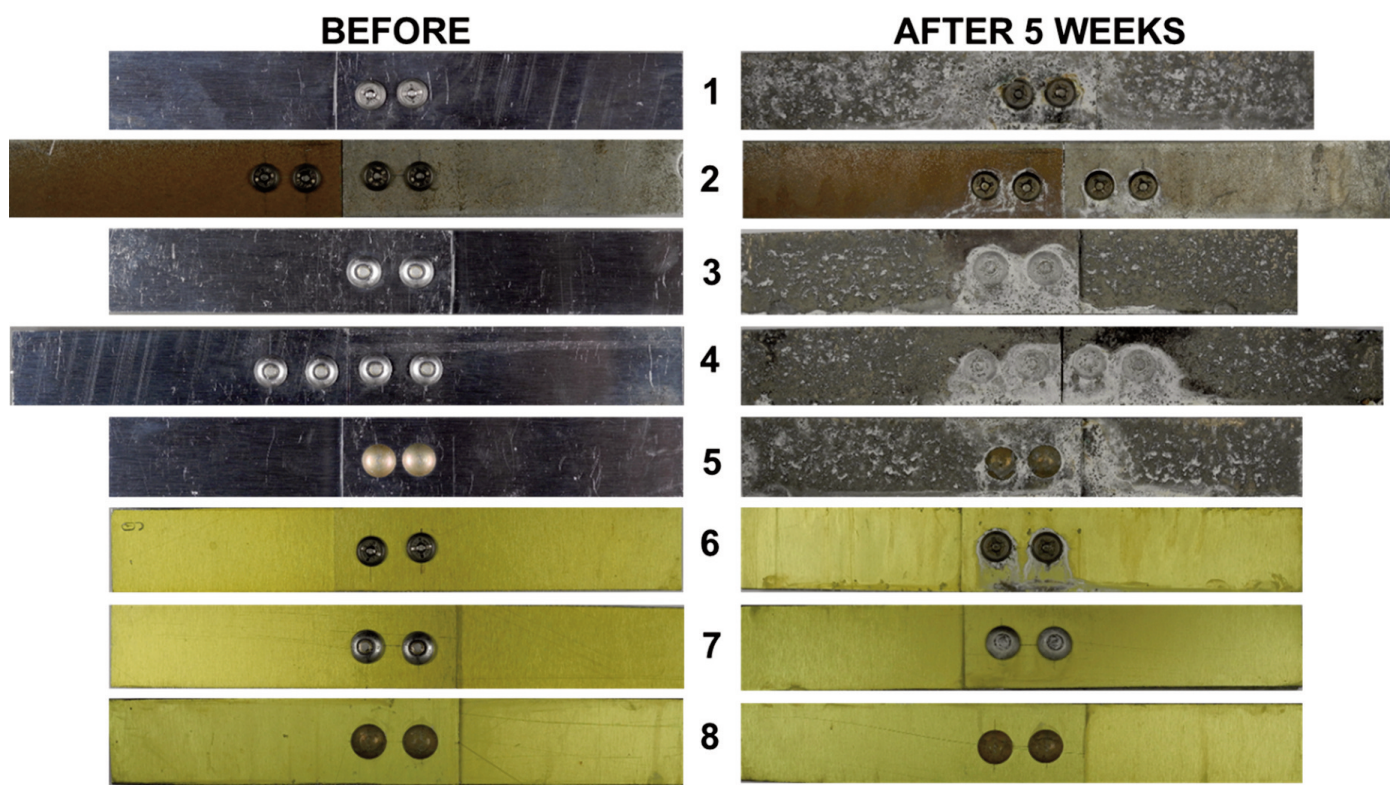

Fig. 5. Photos of specimens before and after the tests in the salt chamber.

The surface of clad sheet specimens after one week testing (168h) demonstrated very intense corrosion. Corrosion occured faster from the side of direct exposure to the flowing stream of salt mist in the chamber (from the side of rivet heads). After 5 weeks, the surface of the clad sheet specimens was completely covered with corrosion products. Therefore the identification of these specimens became much more difficult. The most intense corrosion phenomenon in the form of blue corrosion products could be noticed on specimens riveted with titanium alloys (series 1).

The surface of the specimens from anodized sheets and from the Su-22 aircraft had minor fluid streaking and stains of sediment flowing from unprotected surfaces. However, the most interesting effect could be seen on the specimens in Series 6 and 2. This specimens were made of anodized sheets and rivets made of titanium alloy. Black spots were visible on the specimens in Series 6 near the rivets. They showed the appearance of electrochemical corrosion around the rivets. This coating (without rivets) should last approximately 500 hours. This was confirmed by the fact that on the specimens in Series 7 and 8 including elements made of anodized sheet with aluminum rivets, anodized coating was not damaged.

However, it should be noted that the aircraft's skin is protected against corrosion. Thus, the tested specimens represent the most vulnerable case when the paint coating on the aircraft is damaged. 


\section{Mass measurement}

During the salt spray tests each week, mass measurements were carried out. The results of each series of specimens were plotted as shown below.
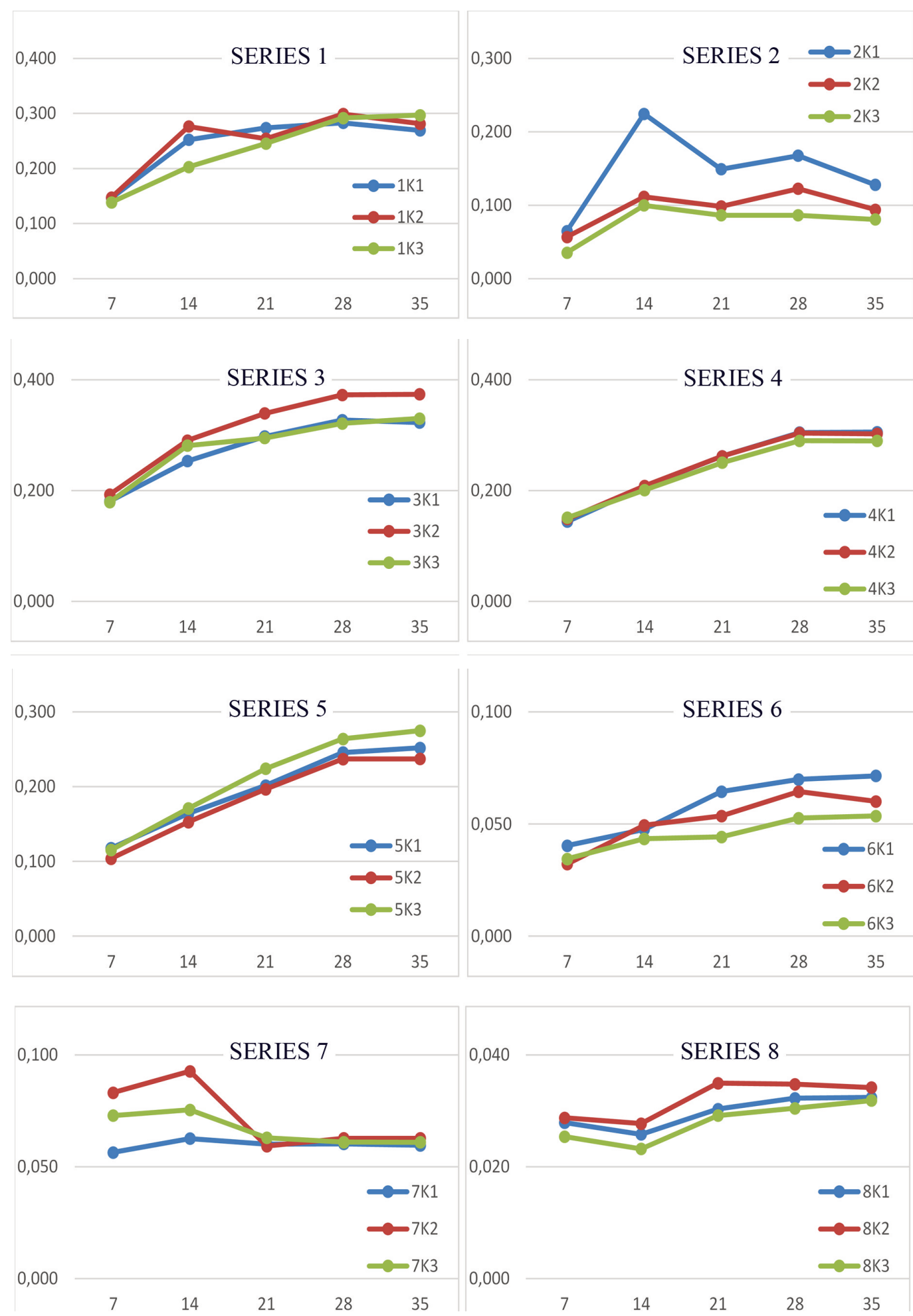

Fig. 6. Charts of specimens mass changes during salt spray tests. 


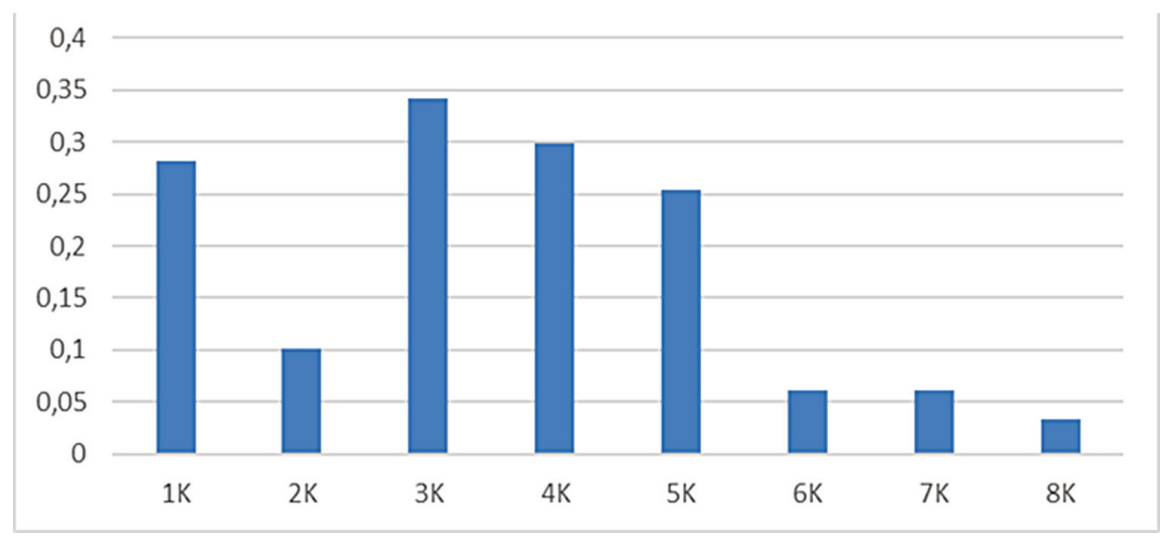

Fig. 7. Graph of the mass change of the specimens after 35 days.

Based on the tests performed, it can be noticed that along with the passage of time the mass of all specimens increases compared to the measurements taken before accelerated aging. There are two main reasons for this. The first reason is the fact that after removing the specimens from the salt chamber, a certain part of the salt solution remains between the sheet elements. It cannot be rinsed out without unriveting the specimens. On the other hand, the increase in the mass of the specimens is more considerably affected by the formation of corrosion products that were not removed. The mass increases the most for specimens made of clad sheet. On anodized sheet specimens, corrosion products are formed mainly on the unprotected edges. The side surface is relatively small.

\section{Strength tests}

\section{Load capacity}

During the tests, the loads at which the specimens were damaged were recorded. The highest value of the load capacity was recorded for the single strap specimens made of sheets from the Su-22 aircraft. However, these specimens had the greatest thickness. The lowest value of the load capacity was shown in specimens made of clad sheet metal and anodized sheet metal connected with ordinary double-sided aluminum rivets (Series 5 and 8 ).

The greatest decrease in load capacity was observed for specimens with titanium alloy joints with clad sheet or plates obtained from fragments of the Su-22 aircraft. After the salt spray tests, the load capacity of these joints was lower by approximately $10 \%$.

Despite the presence of corrosion on the side surface inside the hole for anodized specimens with titanium rivets, an increase in the load capacity was recorded. Nevertheless, it should be noted that the load capacity of connections is significantly influenced by the accuracy of the location of the holes. The slight change in the position of the hole has a significant impact on the value of surface pressure. The analysis of the reference specimens of this series revealed that some of the rivets were slightly closer to the edge. In addition, for specimens in Series 6 the load capacity values after aging had a relatively large deviation. 


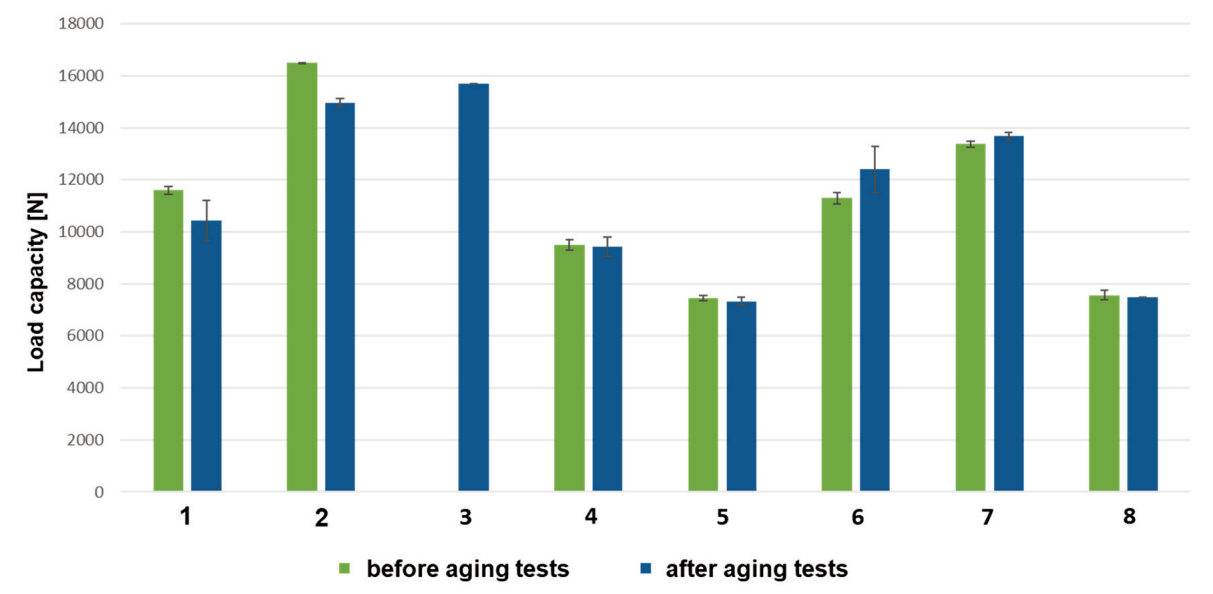

Fig. 8. Graph of the load capacity change of the specimens.

\section{Visual assessment}

Table 3. Specimens after strength test.

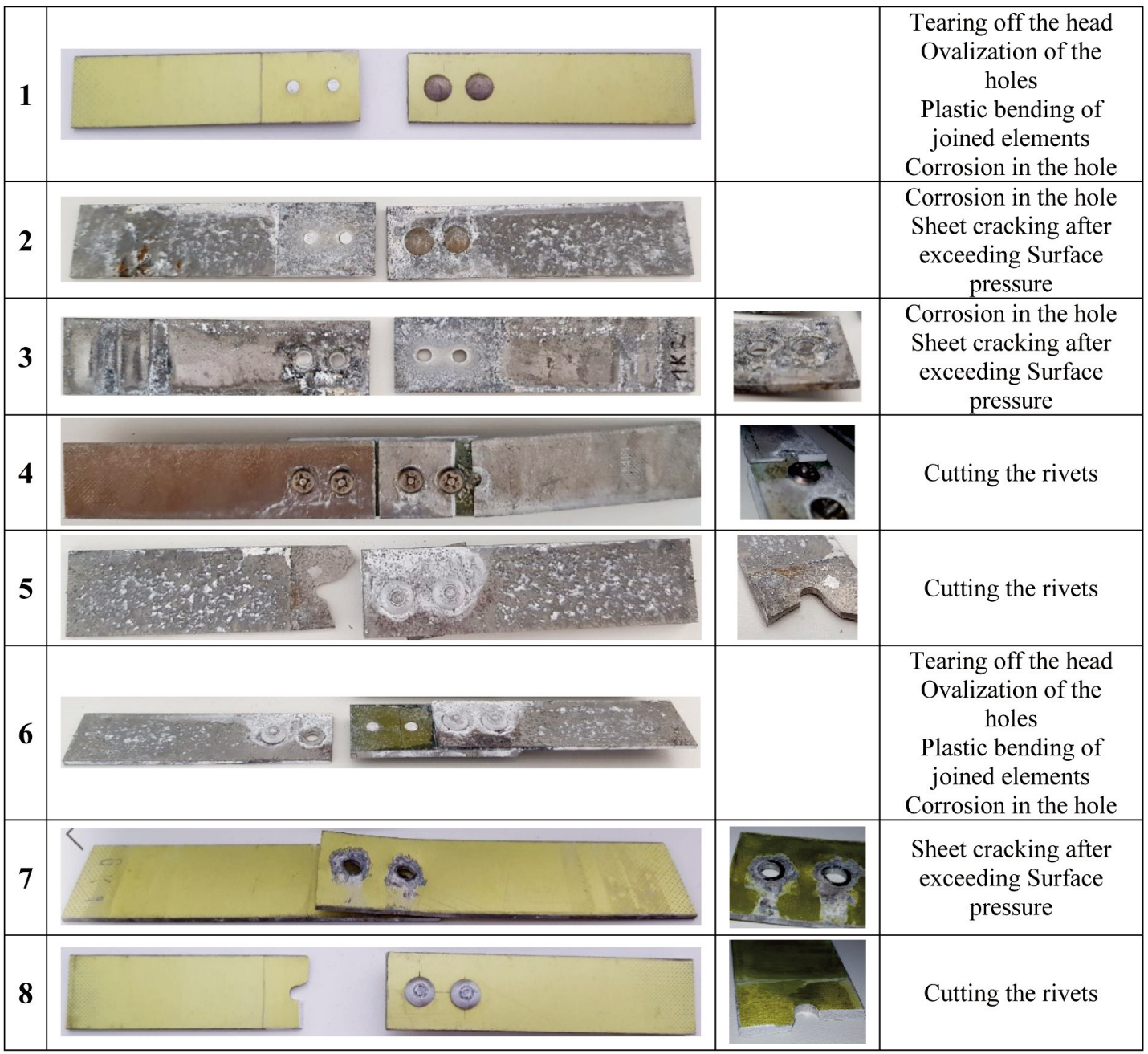


The photos of the specimens with titanium rivets show white corrosion products on the unprotected surface inside the holes. This explains the reduction in the load capacity values for Series 1 and 2 .

Series 1 and 5 (specimens made of clad sheet metal) as well as 6 and 8 (specimens made of anodized sheet metal) had single overlap structures. In Series 1 and 6, titanium rivets were used as fasteners. The form of destruction of these specimens was similar. In both cases, the holes were ovalised due to higher strength properties of the titanium alloy than that of the aluminum alloy. The rivet heads in those joints were detached. Moreover, the photos show the deformation of the riveted specimens after the strength tests. This testifies to the fact that the specimens were simultaneously stretched and bent. Specimens made of anodized sheets showed a slightly higher load capacity.

The specimens in Series 5 and 8 had common aluminum rivets in their construction. In this case, specimens made of anodized sheet also showed slightly higher values of the load capacity. The fracture mechanism in both series of specimens was similar. The damage took the pattern of cutting rivets whose properties did not differ much from the properties of the sheet material.

Specimen in Series 3 and 7 with a double overlap joint structure are connected with single-sided aluminum rivets. In this case, the load capacity of specimens made of anodized sheet is slightly lower than that of the specimens made of clad sheet. In the specimens in both series, the sheet metal cracks occurred when the surface pressure was exceeded, and there were no areas indicative of corrosion on the side surface around the rivet holes.

Based on this analysis, it can be concluded that the load capacity of riveted joints and the pattern of their destruction are affected by the shape of the specimens, and the material of the rivets. Titanium rivets are much harder than aluminum rivets and they show higher strength properties. However, the use of titanium rivets is associated with the risk of electrochemical corrosion in the absence of additional protection, for example in the form of paint coating.

\section{CONCLUSIONS}

- No corrosion was found on the outer surface of the specimen and in the areas of riveted joints of the reference specimens.

- The specimen protected with an anodic coating showed much higher corrosion resistance than specimens made of clad sheet.

- Double-sided aluminum rivets became rapidly covered with white corrosion products.

- Titanium rivets accelerated corrosion.

- Conversion-protected aluminum rivets (Huck) showed the best durability and corrosion protection.

- Corrosion products were not removed therefore a mass increase was recorded.

- The greatest increase in mass was recorded for specimens made of clad sheet.

- The smallest weight gain was recorded for specimens made of anodized sheet.

- A negative effect on the load capacity was observed where titanium rivets were used. 
- For Huck rivets (aluminum) and 3558A-4-10 common rivets, corrosion phenomena did not affect the load capacity.

- The paint coating significantly reduced the development of electrochemical corrosion.

\section{REFERENCES}

[1] Barszcz, P. (2012). Badania korozyjne statków powietrznych w aspekcie zwiększenia resursów oraz eksploatacji wg. stanu technicznego, Prace naukowe ITWL, pp. 45-57.

[2] Song, G., Atrens, A. and Jia, J.X. (2007). Experimental measurement and computer simulation of galvanic corrosion of magnesium coupled to steel, Advanced Engineering Materials, 9, pp. 65-74. https://doi.org/10.1002/adem.200600206.

[3] Höcheb, D., Lamakaa, S., Mira, Z., Hackc, T. and Snihirovaa, D. (2019). Galvanic corrosion of Ti6A14V-AA2024 joints in aircraft environment: Modelling and experimental validation, Corrosion Science, 157, pp. 70-78. https://doi.org/10.1016/j.corsci.2019.04.036.

[4] Kamiński, M. and Baszkiewicz, J. (1997). Podstawy korozji materiałów. Warsaw: Oficyna Wydawnicza Politechniki Warszawskiej. ISBN 978-83-87012-45-8.

[5] Petrović, Z.C. (2016). Catastrophies caused by corrosion, The Vojnotehnički glasnik/Military Technical Courier, 64(4), pp. 1048-1064. https://doi.org/ 10.5937/vojtehg64-10388.

[6] Downer, J. (2010). Anatomy of a disaster: why some accidents are unavoidable, Centre for Analysis of Risk and Regulation, London, ISBN 978-08-53284-03-1.

[7] Crocombe, A.D. and Anwar, S.N.R. (2013). Simultaneously effect of environment and sustained load on the degradation of aluminium bonded joint, International Journal of Materials Science and Applications, 2(6), pp. 204-208. https://doi.org/ 10.11648/j.ijmsa.20130206.16.

[8] Gąsior, J., Komorek, A., Rośkowicz, M. and Tkaczuk, S. (2018). Ocena możliwości zastąpienia nitów typu solid w połączeniach konstrukcji lotniczych, Technologia i automatyzacja montażu, 100(2), pp. 53-56. 